\title{
MECHANICAL DEBURRING OF DRILLING-INDUCED EXIT BURRS IN CARBON FIBRE REINFORCED POLYMER COMPOSITES
}

\author{
András Gödri ${ }^{1}$, AnNA Nikoletta Helle ${ }^{1}$, And Norbert GeIeR*11 \\ ${ }^{1}$ Department of Manufacturing Science and Engineering, Budapest University of Technology and
Economics, Múegyetem rkp. 3, Budapest, 1111, HUNGARY
}

\begin{abstract}
Carbon fibre reinforced polymer (CFRP) composites have excellent specific mechanical properties, which have contributed to the replacement of metallic structural components in high-tech sectors. However, the anisotropic and inhomogeneous properties of CFRPs render them difficult to cut. Burr is one of the main machining-induced macro-geometrical defects in CFRPs. Even though burr does not weaken the resultant strength of the composites (unlike delamination), its removal is time-consuming and costly. The main aim of the present paper is to investigate the efficiency of the mechanical deburring method. Deburring experiments were carried out on unidirectional CFRP, based on a full factorial experimental design using a special solid carbide cutting tool. The effects of feed and cutting speed were analysed using digital image processing and visual evaluation of high-resolution images. The experimental results show that the examined factors seem to have no significant effect on the results over the applied parameter range, because the exit burrs were successfully removed at each parameter setting. Furthermore, during the deburring process, the formation of a significant amount of chamfers was observed. Since the size of the chamfers depends on the size of delamination-induced material deformation and process control, it should be either compensated for or monitored in the future to develop a more reliable deburring process.
\end{abstract}

Keywords: deburring, carbon fibre reinforced polymer, exit burr, drilling, digital image processing

\section{Introduction}

Nowadays, carbon fibre reinforced polymer (CFRP) composites make up a significant proportion of materials used in the automotive, defence, aerospace, marine and space technology industries where it is almost indispensable [?]. The reason for their popularity is due to the fact that they have excellent mechanical properties, however, their anisotropic and inhomogeneous properties cause major problems like delamination, microcracks and burrs which have to be solved in machining. The main machininginduced defects in terms of machining CFRPs are delamination and burrs which bring about inaccuracies and also damage the structure of the workpiece [?].

Although the formation of burrs in quasihomogeneous materials like metals has been studied for decades, research into burr formation in fibrous composites is not that extensive. In fibre reinforced polymer composites, the burr formation mechanism strongly depends on the following five key factors: the material to be machined, the fibre cutting angle $(\theta)$, the machining direction, the supporting plate in use and the cutting edge radius $\left(r_{\beta}\right)$. Four types of chip-removal mechanisms are associated with machining unidirectional CFRPs when the rake angle $(\gamma)$ is positive and the cutting edge radius

\footnotetext{
*Correspondence: geier.norbert@gpk.bme.hu
}

$\left(r_{\beta}\right)$ is small: type $\mathrm{I}: \theta=0^{\circ} / 180^{\circ}$, type II: $\theta=45^{\circ}$, type III: $\theta=90^{\circ}$, and type IV: $\theta=135^{\circ}$. The fibre cutting angle has a significant effect on the texture of the machined surface as well as on the burr formation mechanism [?]. Jia et al. [?] examined the effect of the machining direction at the working point. They observed that in the absence of an external supporting plate, the machining is bending-dominated and the probability of uncut fibres and burrs forming increased. However, if the fibre is supported by either a plate or a material, the machining is fracture-dominated and the possibility of surface damage is minimal.

Fuji et al. [?] investigated the effect of the cutting edge radius and fibre cutting angle on surface defects after machining and found that if $r_{\beta}$ is relatively small, machining will occur with fracture-dominated fibre cutting. However, should $r_{\beta}$ be too large, bending-dominated thread cutting takes place, where there is no guarantee that cutting will be successful. They also studied burr formation during drilling and observed that the area around the hole can be divided into four separate regions, where the boundaries of the regions were chosen based on the fibre cutting angles. These four regions are symmetrical in pairs and the same processes take place in them, as can be seen in Fig. ??. If the fibre cutting angle is within the 


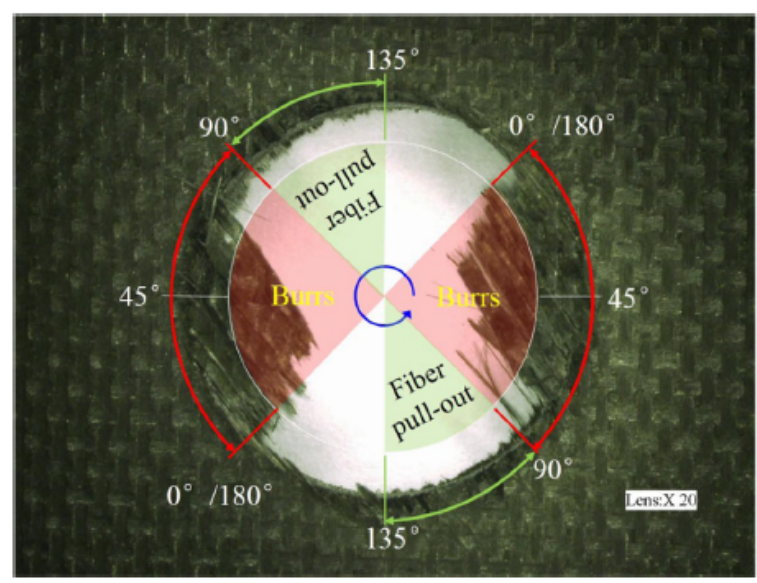

Figure 1: Surface damage as a result of drilling CFRP laminates using a worn tool [?]

range of $90^{\circ}<\theta<180^{\circ}$, the material is machined under favourable conditions. This range is not characterized by burr formation but fibre pull-out occurs more frequently (depicted by the green range in the figure). If the fibre cutting angle is within $0^{\circ}<\theta<90^{\circ}$ (illustrated by the red range in Fig. ??), the tool will machine the material under adverse conditions. Within this interval, if the tool edge radius is large, burrs will always form here.

$\mathrm{Xu}$ et al. [?] examined burr formation, tearing and delamination with a digital microscope and an ultrasonic C-scan technique using three tools with different geometries. They observed that the feed has a significant effect on the extent of drilling defects. They also noted that while the cutting performance of brad and spur drills is the best during drilling, the dagger drill was the least satisfactory.

The primary purpose of machining is to produce clear as well as burr- and damage-free geometrical features. Several suggestions have been made for the parameter set and the use of special cutting tools to ensure damage-free machining. Yu et al. [?] investigated a new tool geometry for CFRP drilling. The double-pointed tool had an extragrooved helical cutting edge, which was significant due to the removal of burrs formed during drilling. The experiment was also performed with a conventional drill as a reference and later compared to the two results which showed that no burrs occurred at the exit point of the holes, even after more than 100 drilling operations had been performed.

In the case of the improper selection of a machining technology and parameters, the remaining burrs can be reduced by deburring methods. Islam et al. [?, ?] investigated the effectiveness of deburring strategies using electrical discharge machining (EDM) and observed that the material removal rate increased for the negatively charged tool and as the capacity increased, the voltage and gas pressure also rose during both solid-state dielectric EDM processes. In addition, compared to conventional oily EDM, oxygen caused the material removal rate to almost triple and that of air to nearly double. Based on these results, it was stated that dry EDM is much more effective than oily EDM with regard to the deburring of CFRP. Park et al. [?] investigated a hybrid cryogenic method for deburring. They compared four setups and established that the final setup was the most effective with a burr removal rate of $100 \%$.

Even though the aforementioned deburring technologies are suitable to remove CFRP burrs, their material removal rate is not as good as the mechanical equivalent. A relatively wide range of cutting tools can be used for mechanical deburring [?], e.g., compact tools that can remove both the entrance and exit burrs (like spiral slot drills) as well as those that can only remove burrs on one side of the composite (like tapered countersink drills). However, since the number of studies examining their effectiveness is relatively low in the field of CFRP deburring, the main aim of the present study is to analyse the mechanical deburring of drilling-induced burrs in unidirectional CFRP composites.

\section{Experimental setups}

The deburring experiments were examined on a predrilled vinyl ester-based unidirectional carbon fibre reinforced polymer (UD-CFRP) plate. The main mechanical properties of the UD-CFRP plate at different fibre orientation angles ( $\Phi$ : angle between the fibre direction and load directions of the mechanical tests) are listed in Table ??. The pre-drilled composite can be seen in Fig. ?? The diameter of the pre-drilled holes was $d=10 \mathrm{~mm}$. Given that the performance of the mechanical deburring was tested on the exit burrs, the entrance burrs were removed by a sheet of sandpaper to prevent them from influencing the evaluation.

The deburring experiments were conducted on a Kondia B640 3-axis machining centre. A Nilfisk GB733 industrial vacuum cleaner was used to remove the carbon fibres from the machining zone. A FRAISA 20340.450 uncoated, solid carbide compression end mill with coarse teeth was used with a diameter of $D=10 \mathrm{~mm}$ and a point angle of $\sigma=135^{\circ}$. The schematic diagram of the

Table 1: Main mechanical properties of the applied UD-CFRP

\begin{tabular}{lllll}
\hline Mechanical properties & $\Phi=0^{\circ}$ & $\Phi=30^{\circ}$ & $\Phi=60^{\circ}$ & $\Phi=90^{\circ}$ \\
\hline Tensile strength (MPa) & $547.85 \pm 45.78$ & $61.22 \pm 5.15$ & $17.36 \pm 1.31$ & $19.01 \pm 1.83$ \\
Charpy impact strength $\left(\mathrm{kJ} / \mathrm{m}^{2}\right)$ & $263.17 \pm 24.76$ & $26.83 \pm 2.24$ & $9.35 \pm 1.16$ & $5.28 \pm 0.20$ \\
Average Shore D hardness (-) & & \multicolumn{2}{c}{$88.2 \pm 0.4$} & \\
Average interlayer shear strength $(\mathrm{MPa})$ & & $21.77 \pm 0.70$ & \\
\hline
\end{tabular}


Table 2: The values of the parameters at different levels

\begin{tabular}{llll}
\hline Parameters & \multicolumn{3}{c}{ Levels } \\
\hline & 1 & 2 & 3 \\
\hline Cutting speed $\left(v_{\mathrm{c}} \mathrm{m} / \mathrm{min}\right)$ & 20 & 60 & 100 \\
Feed $(f \mathrm{~mm} / \mathrm{rev})$ & 0.05 & 0.075 & 0.1 \\
\hline
\end{tabular}

deburring cycle is illustrated in Fig. ??. The applied deburring cycle was a rolling circular interpolation motion, where the cutting point of the tool was at the middle of the main cutting edge at the point denoted by $T$ in the absence of a cooling fluid. The experiments were designed by the full factorial method. The parameter set was chosen based on previous works [?,?] and suggestions from tool producers. The parameter sets can be seen in Table
??. The set values of the parameters are interpreted at the $T$ position of the cutting tool. Each experimental setting was repeated five times and their order was randomized to eliminate hidden errors during the experiment. A DinoLite Premier AD7013MZT digital handheld microscope was applied for image capturing before and after deburring. The drilled and deburred holes were captured by the microscope from the top side while they were illuminated from the bottom side by an LED source to improve the contrast of the images. The digital images taken before and after deburring were processed to determine the burr area $\left(A_{\mathrm{b}}\right)$. The main steps of the digital image processing are illustrated in Fig. ??. Firstly, the original image was taken, before being filtered and segmented in the second step. Finally, the image was cut to form a particular shape

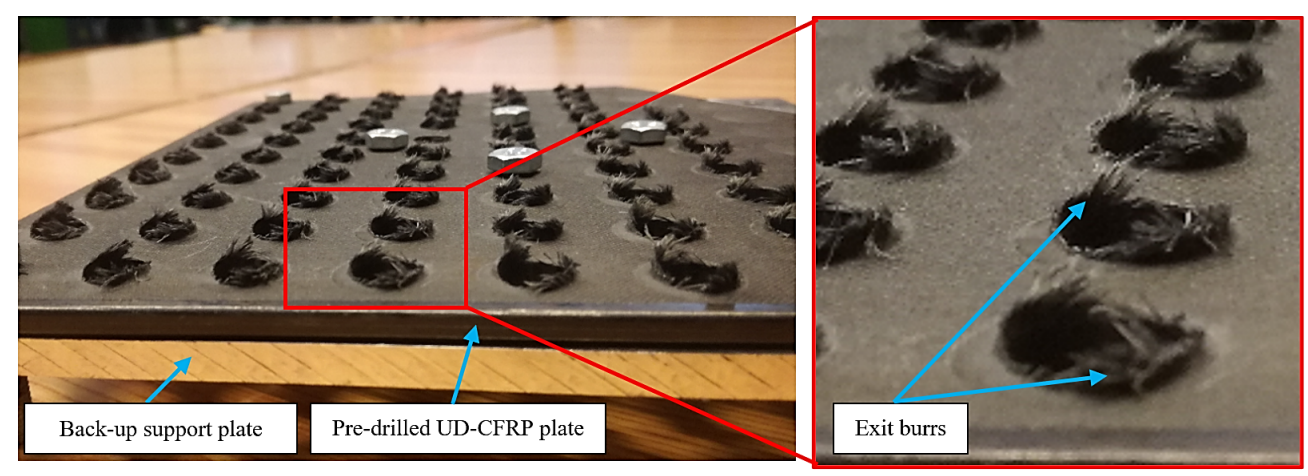

Figure 2: Drilling-induced exit burrs at the edges of the pre-drilled holes in the CFRP composite

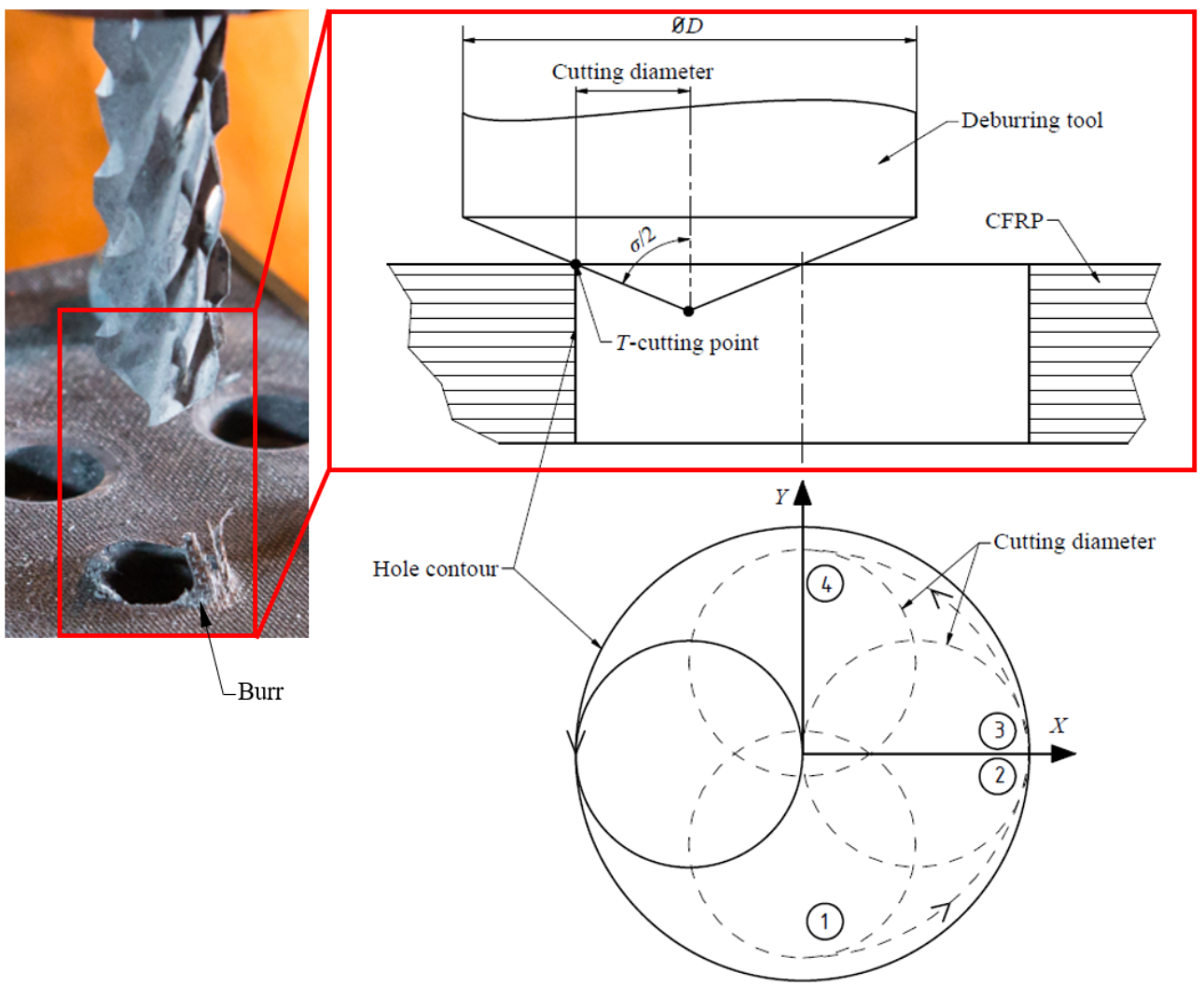

Figure 3: The rolling circular interpolation motion and the $T$ cutting point of the tool 

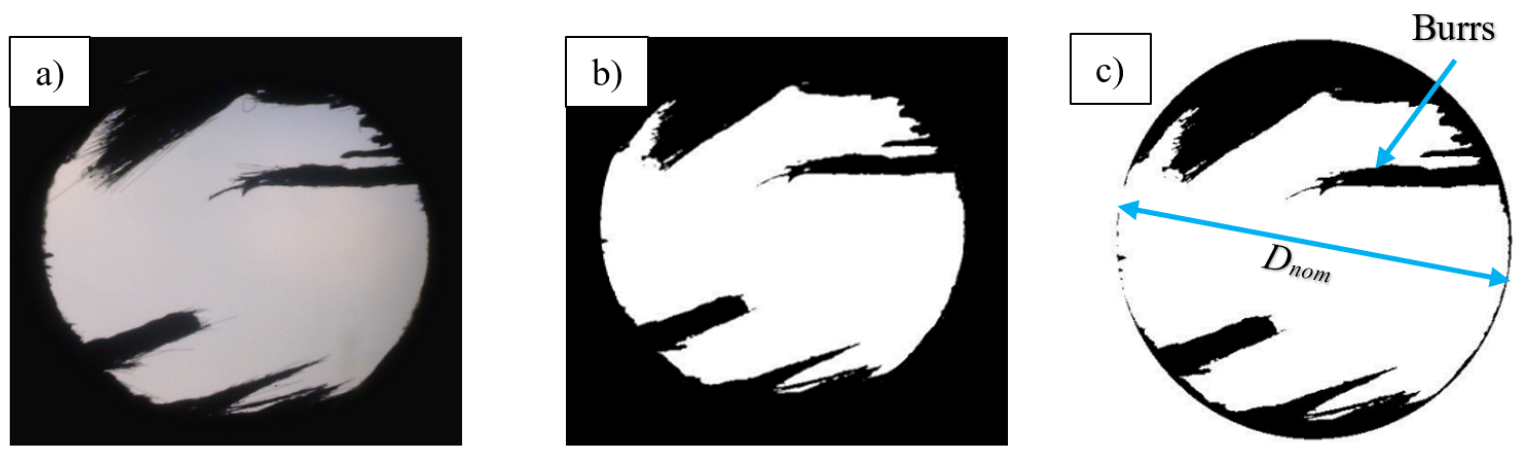

Figure 4: Main steps of the digital image processing method: (a) original image, (b) filtered and segmented image, (c) cut around hole

in order to determine the burred area parameter by pixel counting and transformation. The $A_{\mathrm{b} 0}$ parameters, which are listed in Table ??, were determined before the deburring experiments.

\section{Results and discussion}

The efficiency of mechanical deburring was examined in this study on drilling-induced exit burrs by comparing the parameters $A_{\mathrm{b} 0}$ and $A_{\mathrm{b}}$. Each parameter was determined by a digital image processing method of images taken before and after deburring. The digital image processed holes - before and after deburring - are summarised in Fig. ??. As can be seen, the holes contained a significant amount of burr before deburring, which was radically reduced by the applied deburring cycle. It can be stated that the deburring experiment was successfully completed. In addition, based on the images, the examined parameters seem to have no significant effect on the results because the exit burrs were totally removed under all experimental conditions. Furthermore, some remaining burrs can be seen on the post-deburring photos. These errors could be the result of the following three main issues: (i) an error in terms of the digital image processing method could distort the filtered and segmented photos, (ii) the inner surface of the holes can reflect light or contain some uncut fibre which can also distort the photos, and (iii) if the entrance side of the hole contour contains burrs or uncut fibres, these will be visible on images as well as disfigure the filtered and segmented photos.

The $A_{\mathrm{b}}$ parameters were also determined by the digital image processing method. In Fig. ??, the parameters $A_{\mathrm{b} 0}$ and $A_{\mathrm{b}}$ were both depicted so they can be easily compared. These $A_{\mathrm{b}}$ values were consistent with the photos. It can be seen on the diagram that the deburring cycle minimized the average amount of burr $\left(A_{\mathrm{b}}=2.496 \mathrm{~mm}^{2}\right)$, where the standard deviation was relatively low $\left(s\left(A_{\mathrm{b}}\right)=0.422 \mathrm{~mm}^{2}\right)$.

In addition to the analysis of the burred area, the deburred workpiece was quantitatively evaluated by taking a high-resolution photo of each hole which were then visually evaluated by searching for machining-induced surface defects, e.g., uncut fibres, fragmentation, delamination, burr formation and burnout. These enlarged images of the holes present all the macro-type errors which could be observed and identified (Fig. ??a-h). The properties of the critical holes can be seen in Table ??. It was observed that the macro-type errors were characteristically uncut fibres. It can also be noticed that the defects mostly appeared symmetrically on the chamfers as a result of the directional dependence of the unidirectional CFRP plate, as was also observed by Fuji et al. [?].

It can be seen that 4 out of the 5 repetitions with the parameters $v_{\mathrm{c}}=20 \mathrm{~m} / \mathrm{min}$ and $f=0.1 \mathrm{~mm} / \mathrm{rev}$ contained macro-type errors, so this parameter set can be identified as the most unfavourable setup and the set $v_{\mathrm{c}}=60 \mathrm{~m} / \mathrm{min}$ and $f=0.1 \mathrm{~mm} / \mathrm{rev}$ with 3 out of the 5 repetitions containing such areas as the second least

Table 3: Burr areas before deburring $\left(A_{\mathrm{b} 0}\right)$

\begin{tabular}{ll|ll|ll|ll|ll}
\hline No. & $A_{\mathrm{b} 0}\left(\mathrm{~mm}^{2}\right)$ & No. & $A_{\mathrm{b} 0}\left(\mathrm{~mm}^{2}\right)$ & No. & $A_{\mathrm{b} 0}\left(\mathrm{~mm}^{2}\right)$ & No. & $A_{\mathrm{b} 0}\left(\mathrm{~mm}^{2}\right)$ & No. & $A_{\mathrm{b} 0}\left(\mathrm{~mm}^{2}\right)$ \\
\hline 1 & 22.0168 & 10 & 15.9655 & 19 & 17.1038 & 28 & 12.7630 & 37 & 15.5607 \\
2 & 16.3193 & 11 & 12.5244 & 20 & 11.7950 & 29 & 13.7123 & 38 & 17.7133 \\
3 & 17.6914 & 12 & 12.1362 & 21 & 11.8991 & 30 & 27.4602 & 39 & 14.9731 \\
4 & 15.9935 & 13 & 10.3192 & 22 & 22.1512 & 31 & 18.0514 & 40 & 25.4493 \\
5 & 14.1156 & 14 & 23.8615 & 23 & 16.8891 & 32 & 19.2630 & 41 & 17.4130 \\
6 & 16.0116 & 15 & 14.4638 & 24 & 13.9843 & 33 & 12.6162 & 42 & 14.4501 \\
7 & 13.0983 & 16 & 11.1045 & 25 & 11.8457 & 34 & 14.7083 & 43 & 22.6858 \\
8 & 16.6144 & 17 & 13.7582 & 26 & 12.8019 & 35 & 33.3027 & 44 & 14.4981 \\
9 & 20.3942 & 18 & 12.2648 & 27 & 15.2845 & 36 & 14.7146 & 45 & 12.4184 \\
\hline
\end{tabular}




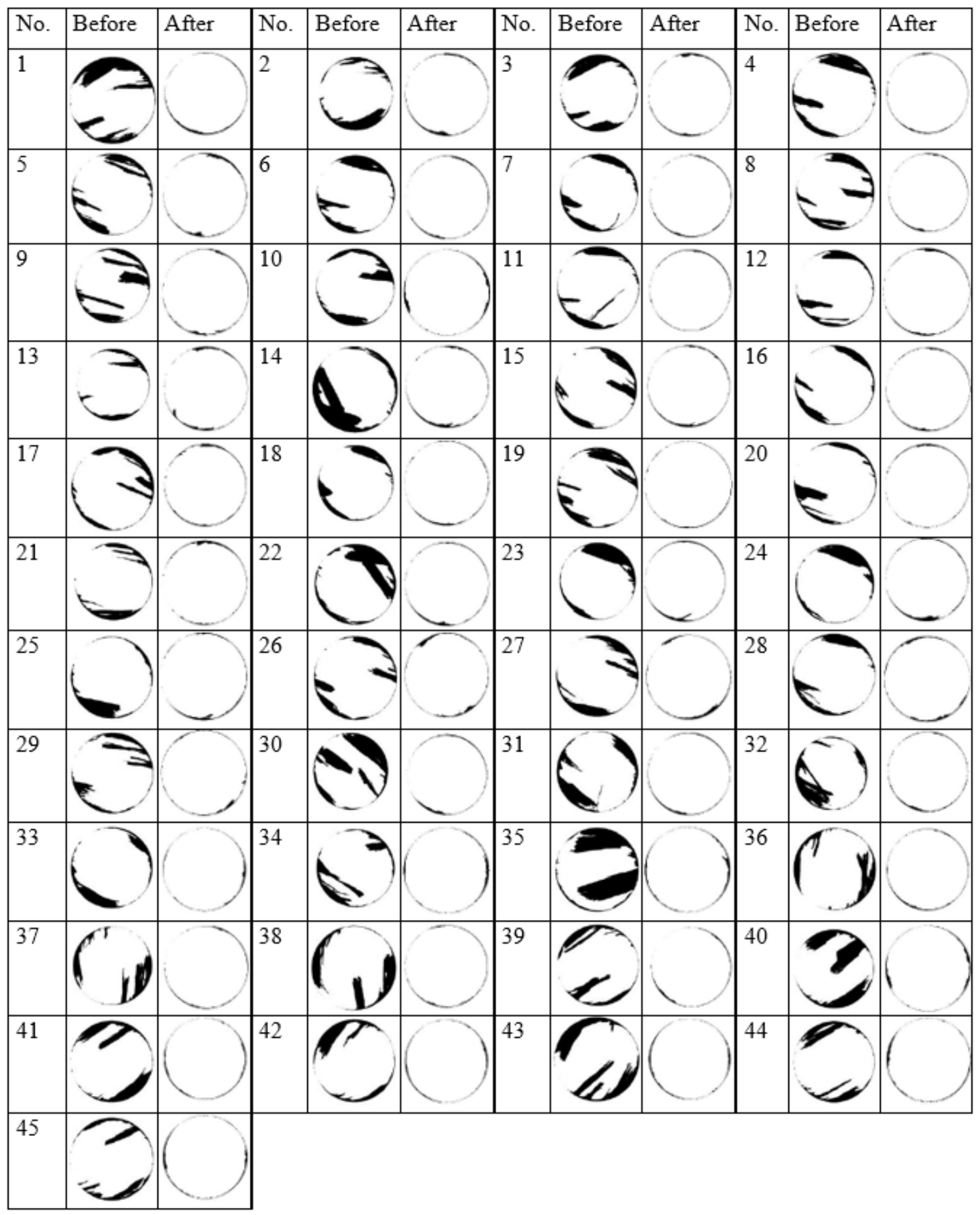

Figure 5: The digital image processed holes - before and after deburring

favourable. Only 1 out of the 5 repetitions for the parameter set $v_{\mathrm{c}}=20 \mathrm{~m} / \mathrm{min}$ and $f=0.01 \mathrm{~mm} / \mathrm{rev}$ consisted of macro-type errors, possibly as a result of a random influential effect. No macro-type errors were visible by the naked eye in the other holes.

By taking into account that each experimental setup analysed resulted in efficient deburring, the maximum $v_{\mathrm{c}}=100 \mathrm{~m} / \mathrm{min}$ and $f=0.1 \mathrm{~mm} / \mathrm{rev}$ is recommended to achieve the maximum material removal rate (MRR).

Although the present experimental results show that the developed mechanical deburring technology is efficient over the whole analysed parameter range of $v_{\mathrm{c}}=$ $20-100 \mathrm{~m} / \mathrm{min}$ and $f=0.05-1 \mathrm{~mm} / \mathrm{rev}$, a significant degree of chamfer formation was observed. Since the size of these chamfers probably depends on the size of delamination-induced material deformations and process control, this should be compensated for or monitored in the future. 


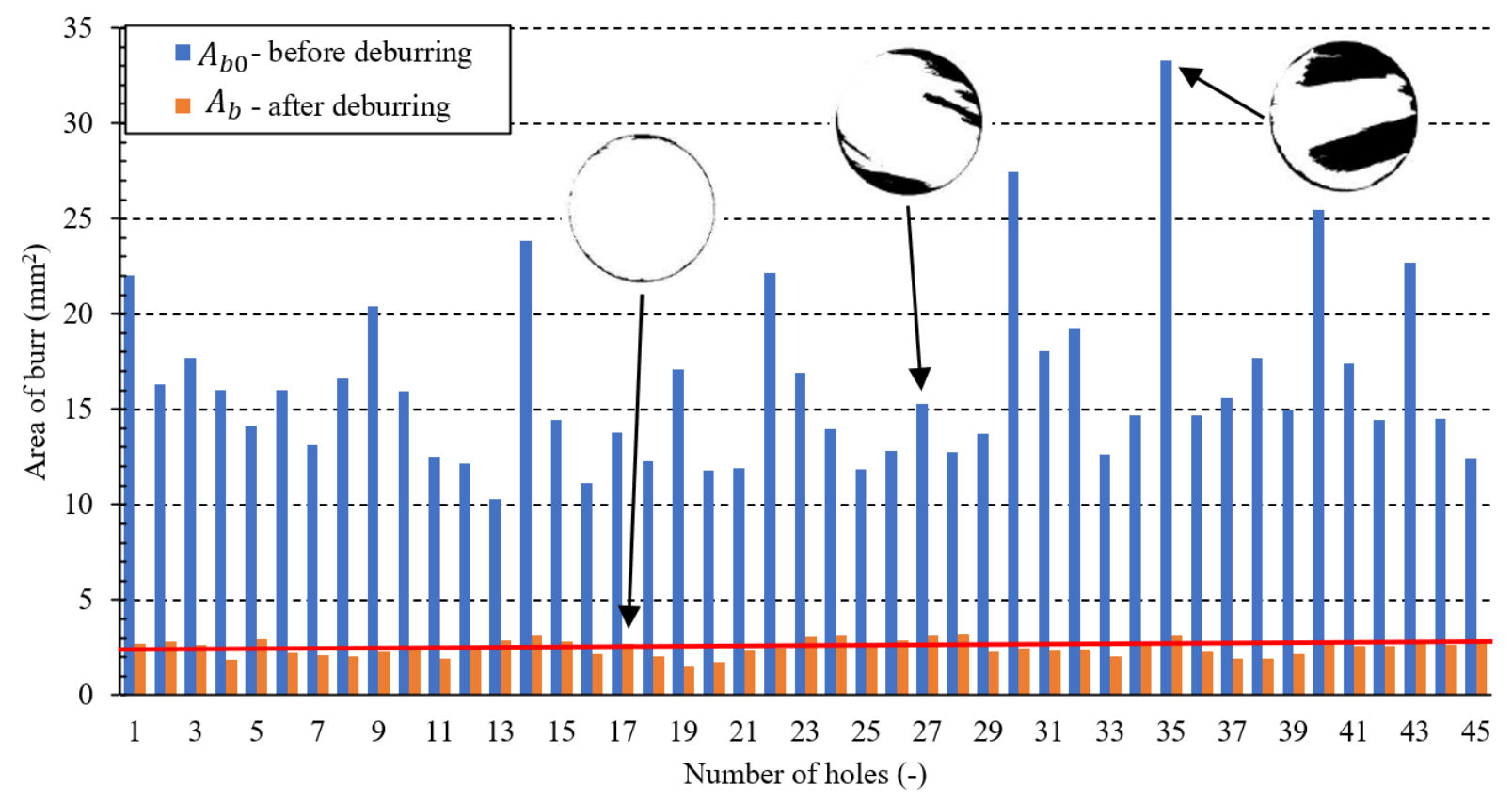

Figure 6: Comparison of burr areas before $\left(A_{\mathrm{b} 0}\right)$ and after $\left(A_{\mathrm{b}}\right)$ the applied deburring cycle 8
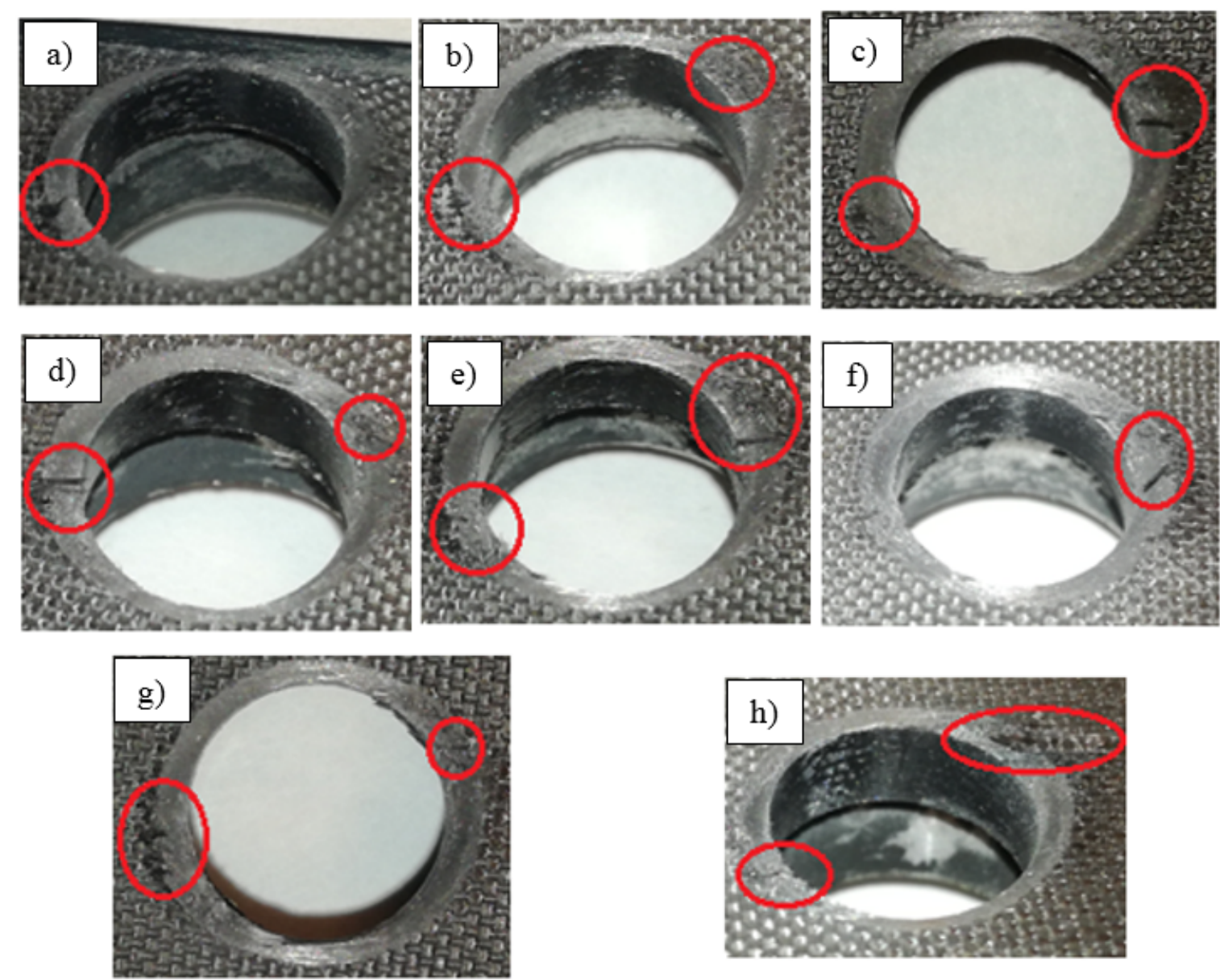

Figure 7: The holes with observed macro-type errors: a) burrs, b) uncut fibres and rough surface roughness, c) burrs and uncut fibres, d) uncut fibres and rough surface roughness, e) rough surface roughness, f) uncut fibres, g) burrs and uncut fibres, $h$ ) rough surface roughness and delamination 
Table 4: Properties of the holes containing macro-type errors

\begin{tabular}{|c|c|c|c|}
\hline \multirow[t]{2}{*}{$\begin{array}{l}\text { Presented } \\
\text { picture }\end{array}$} & \multirow[t]{2}{*}{ No. of hole } & \multicolumn{2}{|c|}{$\begin{array}{l}\text { Applied parameters } \\
\text { during deburring }\end{array}$} \\
\hline & & $v_{\mathrm{c}}(\mathrm{m} / \mathrm{min})$ & $f(\mathrm{~mm} / \mathrm{rev})$ \\
\hline a) & 4 & 20 & 0.1 \\
\hline b) & 5 & 20 & 0.1 \\
\hline c) & 13 & 20 & 0.01 \\
\hline d) & 15 & 60 & 0.1 \\
\hline e) & 17 & 60 & 0.1 \\
\hline f) & 20 & 20 & 0.1 \\
\hline g) & 39 & 20 & 0.1 \\
\hline h) & 45 & 60 & 0.1 \\
\hline
\end{tabular}

\section{Conclusions}

In the present study, the influence of the cutting speed $\left(v_{\mathrm{c}}\right)$ and feed $(f)$ on the efficiency of mechanical deburring was experimentally analysed. The efficiency of mechanical deburring was examined by digital image processing. According to the present study, the following conclusions can be drawn:

- The applied mechanical deburring technology successfully removed all CFRP burrs in each experimental setup.

- The experimental results show that neither the feed nor the cutting speed have a significant influence on deburring over the analysed parameter range.

- According to the quantitative evaluation, the observed holes with macro-type errors show that the parameters $v_{\mathrm{c}}=20 \mathrm{~m} / \mathrm{min}$ and $f=0.1 \mathrm{~mm} / \mathrm{rev}$ can be identified as the most unfavourable setup, followed by the parameter set $v_{\mathrm{c}}=60 \mathrm{~m} / \mathrm{min}$ and $f=0.1 \mathrm{~mm} / \mathrm{rev}$.

- As the mechanical deburring was successful when implementing each parameter set, it is recommended that the maximum parameters $v_{\mathrm{c}}=100$ $\mathrm{m} / \mathrm{min}$ and $f=0.1 \mathrm{~mm} / \mathrm{rev}$ be applied in order to maximise the material removal rate (MRR).

- During the deburring process, a significant degree of chamfer formation was observed. Since the size of these chamfers depends on the size of the delamination-induced material deformations and process control, this should be compensated for or monitored in the future.

\section{Acknowledgements}

This research reported in this paper and carried out at BME was partly supported by the National Research, Development and Innovation Office (NKFIH) No. OTKAPD20-134430, the NRDI Fund (TKP2020 NC, Grant No. BME-NC) based on the charter of bolster issued by the NRDI Office under the auspices of the Ministry for Innovation and Technology, and the project "Centre of Excellence in Production Informatics and Control"
(EPIC) No. EU H2020-WIDESPREAD-01-2016-2017TeamingPhase2-739592. The authors acknowledge the support of Csongor Pereszlai and Dániel István Poór in their experimental work.

\section{REFERENCES}

[1] Poór, D. I.; Geier, N.; Pereszlai, C.; Xu, J.: A Critical Review of the Drilling of CFRP Composites: Burr Formation, Characterisation and Challenges. Compos. B Eng. 2021, 223, 109155 DOI: 10.1016/j.compositesb.2021.109155

[2] Geier, N.; Davim, J. P.; Szalay, T.: Advanced Cutting Tools and Technologies for Drilling Carbon Fibre Reinforced Polymer (CFRP) Composites: A Review. Compos. A Appl. Sci. 2019, 125, 105552 DOI: 10.1016/j.compositesa.2019.105552

[3] Jia, Z.; Fu, R.; Niu, B.; Qian, B.; Bai, Y.; Wang, F.: Novel Drill Structure for Damage Reduction in Drilling CFRP Composites. Int. J. Mach. Tools Manuf. 2016, 110, 55-65 DOI: 10.1016/j.ijmachtools.2016.08.006

[4] Wang, F-j., Yin, J.-w.; Ma, J.-w.; Jia, Z.-y.; Yang, F.; Niu, B.: Effects of Cutting Edge Radius and Fiber Cutting Angle on the Cutting-Induced Surface Damage in Machining of Unidirectional CFRP Composite Laminates. Int. J. Adv. Manuf. Technol. 2017, 91, 3107-3120 DOI: 10.1007/s00170-017-0023-9

[5] Xu, J.; Li, C.; Mi, S.; An, Q.; Chen, M.: Study of Drilling-Induced Defects for CFRP Composites Using New Criteria. Compos. Struct. 2018, 201, 10761087 DOI: 10.1016/j.compstruct.2018.06.051

[6] Yu, Z.; Li, C.; Kurniawan, R.; Park, K. M.; Ko, T. J.: Drill Bit with a Helical Groove Edge for Clean Drilling of Carbon Fiber-Reinforced Plastic. J. Mater. Process. Technol., 2019, 274, 116291 DOI: 10.1016/j.jmatprotec.2019.116291

[7] Islam, M. M.; Li, C. P.; Won, S. J.; Ko, T. J.: A Deburring Strategy in Drilled Hole of CFRP Composites Using EDM Process. J. Alloys Compd. 2017, 703, 477-485 DOI: 10.1016/j.jallcom.2017.02.001

[8] Islam, M. M.; Li, C. P.; Ko, T. J.: Dry Electrical Discharge Machining for Deburring Drilled Holes in CFRP Composite. Int. J. Precis. Eng. and Manuf. Green Tech. 2017, 4(2), 149-154 DOI: 10.1007/s40684017-0018-x

[9] Park, K. M.; Kurniawan, R.; Yu, Z.; Ko, T. J.: Evaluation of a Hybrid Cryogenic Deburring Method to Remove Uncut Fibers on Carbon Fiber-Reinforced Plastic Composites. Int. J. Adv. Manuf. Technol. 2019, 101(5), 1509-1523 DOI: 10.1007/s00170-018$3045-\mathrm{z}$

[10] Sorrentino, L.; Turchetta, S.; Bellini, C.: A New Method to Reduce Delaminations during Drilling of FRP Laminates by Feed Rate Control. Compos. Struct. 2018, 186, 154-164 DOI: 10.1016/j.compstruct.2017.12.005 